Volume 12 | Issue1

December 2021

\title{
The Centrality of Education for Indigenous Income Mobility in Canada
}

\author{
Michael Haan \\ University of Western Ontario, Canada, mhaan2@uwo.ca \\ Georgina Chuatico \\ University of Western Ontario, Canada, georgina.chuatico@uwo.ca \\ Jules Cornetet \\ Ecole normale supérieure, de Cachan, France, jules.cornetet@ens-cachan.fr
}

Recommended Citation

Haan, M., Chuatico, G., \& Cornetet, J. (2021). The centrality of education for Indigenous income mobility in Canada. The International Indigenous Policy Journal, 12(1). https://10.18584/iipj.2021.12.1.8388 


\title{
The Centrality of Education for Indigenous Income Mobility in Canada
}

\begin{abstract}
In this article, we employ a multinomial logistic regression model to determine which factors predict middle- and upper income class belonging among Indigenous and non-Indigenous people. We examine the impact of identity, education, occupation, and urbanization on income status. The positive impact of higher education is captured by the model; however, post-secondary education has a greater impact on some Indigenous groups than others. We present interaction terms between education and identity to show that investment in higher education is crucial to Indigenous people's income attainment; however, some identity groups benefit more than others.
\end{abstract}

\section{Keywords}

Education, socioeconomic mobility, income, Indigenous Peoples, Canada

\section{Creative Commons License (a) $\mathbb{( \oplus \Theta \Theta}$}

This work is licensed under a Creative Commons Attribution-Noncommercial-No Derivative Works 4.0 License. 


\section{The Centrality of Education for Indigenous Income Mobility in Canada}

Canada's history of colonization and State regulation gave rise to social structures that created different socioeconomic opportunities for Indigenous Peoples and non-Indigenous peoples. Over time, social class gaps between non-Indigenous and Indigenous people have persisted; however, the average income disparity decreased slightly between 1996 to 2006 (Lamb et al., 2018). Most of the gains within Indigenous populations came from improvements in the position of those who were already higher income earners, while those who were in lower income groups fared worse (Lamb, 2013).

In general, social class hierarchies are created and reproduced through economic capital, cultural capital, education, and occupation (De Graaf, 1991; DiMaggio \& Mukhtar, 2004; Katz-Gerro, 2002; Kraaykamp \& Nieuwbeerta, 2000; Lopéz-Sintas \& Katz-Gerro, 2005; Peterson \& Simkus, 1992). The distribution of social class also intersects with Canada's history of colonization and racism, and contemporary social structures. Indigenous people have been oppressed by the system set in place through colonization and State control (Distasio et al., 2005; Menzies, 2006; Patrick, 2014). In addition, colonial oppression created an intergenerational legacy of trauma, contributing to higher rates of substance abuse, violence, poverty, and lower educational attainment and economic outcomes. In turn, these factors contribute to a higher risk of social and economic disadvantage (Oelke et al., 2016). Persistent social and economic inequality between Indigenous and non-Indigenous populations is a frequent theme in the literature (Heisz, 2007; Lamb et al., 2018; Parriag \& Chaulk, 2013). Parriag and Chaulk (2013) found that urban Indigenous people had a lower average income compared to nonIndigenous people, but they also found evidence of a growing Indigenous middle class that demographically resembles middle-income non-Indigenous Canadians in many ways. A critical finding in their work is that the basic human capital model, which posits that higher levels of education and training lead to better economic returns (Becker, 1992), applies to Indigenous people, especially in the middle class and among those who are employed. However, the returns on education and training investment are not distributed evenly across Indigenous and non-Indigenous populations, and it is not clear from Parriag and Chaulk's research why this is the case.

Our study builds on Parriag and Chaulk's (2013) research in several important ways. First, we use the 2016 Census in order to examine the whole country (rather than just urban centres). Second, we use multinomial logistic regression models to look at the comparative effect of socio-demographic, geographic, and human capital characteristics on income level. Finally, like Parriag and Chaulk, we look at Indigenous identity groups separately-Métis, First Nations (Status and non-Status), and Inuit.

In this article, we investigate factors that are associated with the likelihood of being in the lower, middle-, or upper income group. In the sections below, we first review the relevant literature on socioeconomic mobility, focusing on the importance of Indigenous identity, education, occupation, and urbanization in gaining and maintaining middle- and upper income status. Then, using the 2016 Census, we employ multinomial logistic regression models to determine whether these factors predict income group. We conclude by discussing the implications of our research for policy purposes and for future research. 


\section{Literature Review}

\section{Indigenous Identity Groups}

Indigenous identities, which include Status and non-Status First Nations, Métis, and Inuit, are correlated with income distribution and labour market access and opportunities within the Indigenous population in both historical and contemporary contexts (Lamb, 2013). Paternalistic legislation has shaped legal definitions of identity among Indigenous Peoples, which has systematically affected their socioeconomic position in Canada.

The Indian Act, first enacted in 1876 specified who was an "Indian" and therefore entitled to rights under the Act. The Indian Act only recognized First Nations who met certain criteria, which gave them "Indian Status." It also defined entitlement to reserve lands. The Indian Act (1985) defines a reserve as a "tract of land, the legal title to which is vested in Her Majesty, that has been set apart by her Majesty for the use and benefit of a band" (Section 2(1), Reserve, a). At the same time, the Indian Act placed social and economic barriers on Status First Nations. Colonial government officials chose the location of reserves, which were often selected because they had limited economic potential. For example, many were in isolated locations, which constrained their economic growth (Gerber, 2014). Historically, First Nation women and their children lost their Status Rights when they married non-Indigenous men. It was not until 1985, when Bill C-31 was passed, that these rights were restored (Coates, 1999). In the late 1800s, First Nations who chose to pursue higher education, work in professional occupations, or own land lost their Indian Status (Coates, 1999). An amended version of the Indian Act is still in effect today.

Not all Indigenous Peoples in Canada have Status Rights. Non-Status First Nations, for example, do not have the Status Rights under the Indian Act, which includes the right to live on reserve. As a result, they often live in urban centres (Coates, 1999). Although Inuit, Indigenous people of the Arctic, were classified as "Indians" under the Royal Proclamation of 1763 and Constitution Act of 1867, they remain distinct from First Nations in legislation and governance (Bonesteel, 2008). Finally, Métis people are those who have Indigenous and non-Indigenous ancestry stemming from the fur trade in the Northwest of Canada in the $18^{\text {th }}$ century (Coates, 1999). They make up a distinct cultural group in Canada, who, like non-Status First Nations people, do not have Status Rights.

The histories of Indigenous Peoples have shaped their contemporary circumstances. For example, Lamb et al. (2018) found Métis people had the smallest wage disparity, while First Nations living on reserve were found to have the largest disparity. These trends have been identified in other studies (George \& Kuhn, 1994; Lamb, 2013; Pendakur \& Pendakur, 2011).

\section{Education}

Most studies show that the level of education matters. The traditional human capital model posits that high human capital yields to high economic returns. Education and training are forms of human capital that generally place individuals at an advantage in the labour market (Becker, 1992). Those who have the appropriate credentials can find better opportunities and reach middle- and upper class status (Goux \& Maurin, 2012). Consequently, investing in education and training can give an individual higher returns in the labour market (Fan et al., 2017). 
Haan et al.: Centrality of Education for Indigenous Income Mobility

The history of Indigenous education in Canada is filled with stories of horror. At time of writing, 215 children's bodies had been discovered in a mass grave at Kamloops residential school, with widespread expectations to find more, according to First Nations National Chief Perry Bellegarde (Pruden \& Kirkup, 2021). Even for those who did not attend residential schools, lower quality of education, lack of cultural appropriateness, and underfunding remain issues disproportionately experienced by Indigenous students to this day. These issues are systemic across the entire educational spectrum, beginning in elementary schools and continuing all the way to universities (McMahon, 2014).

Education is a critical part of Indigenous class mobility (Gordon \& White, 2014). Education plays an important role in attaining labour market success and thus higher social class status as well. First and foremost, there is a strong correlation between education and employment. Luffman and Sussman (2007) found that having post-secondary education increases the likelihood of employment, and that the effect was particularly strong for women with a university degree. Bougie et al. (2013) also reported that a lack of educational credentials was a barrier to finding employment among unemployed Indigenous people living off reserve. Indigenous people who did not complete high school reported significant barriers to furthering their education.

Yet, gaps persist between Indigenous and non-Indigenous populations. Between 1996 and 2011, a 20percentage point gap existed between Indigenous and non-Indigenous populations in post-secondary education attainment (White \& Peters, 2013). White and Peters (2013) predicted this gap would remain between Indigenous and non-Indigenous people and grow wider for Status First Nations and Inuit under the current policy system.

Differences in average levels of education are also found between Indigenous identity groups, which partially explains why some groups have higher labour market outcomes than others (Ponting, 2005; Wotherspoon \& Satzewich, 1993). In 2012, among off-reserve Indigenous people aged 18 to 44, 23\% of First Nations had completed post-secondary schooling, compared to $47 \%$ of Métis and $26 \%$ of Inuit (Bougie et al., 2013). The variations in educational achievement across Indigenous groups are an important component to understanding their socioeconomic position, as both human capital and identity go hand-in-hand in determining income. We expect that higher levels of education will positively predict middle-and upper income status and reduce the size of the unexplained differences in class membership.

\section{Occupation}

Occupation is another important factor that is linked to income and economic mobility between groups (Kambourov \& Manovskii, 2009; Zangelidis, 2008). Occupation reflects a range of educational qualifications, skills, and attributes that cannot always be fully measured (Fan et al., 2017). Indigenous people are found in certain occupational sectors more than others, which results in labour market segregation based on skill level and occupational prestige. A large proportion of Indigenous people who pursue post-secondary education obtain a trades certificate or college diploma (Luffman \& Sussman, 2007), which corresponds to trades being the second highest occupational category among off-reserve Indigenous people in Western Canada. Additionally, Indigenous people who have a bachelor's degree tend to choose different career paths than their similarly educated non-Indigenous counterparts. Luffman and Sussman (2007), for example, found that Indigenous people who have a university degree 
are likely to work in health, as well as in parks, recreation, and fitness; while non-Indigenous people with a university degree are more likely to work in fields such as engineering technologies. In turn, Indigenous people are underrepresented in knowledge-sector and high-skill occupations. In 2015, there were fewer Indigenous people than non-Indigenous people working in knowledge sectors such as professional, managerial, and technical occupations (Statistics Canada, 2017a), as well as in prestigious occupations such as law and medicine (Moyser, 2017). On the other hand, more Indigenous people work in trades and transport and as equipment operators in natural resources, agriculture, and production, and in sales and services (Statistics Canada, 2017a). Thus, many Indigenous people are often found in occupational sectors that do not require a university education.

Although many Indigenous people work in low-income jobs and work fewer hours, there are also those who work in occupations affiliated with higher class status. A growing number of Indigenous people, especially those living in cities, work in sales and service, professional, management, and trades and transport sectors, which are associated with middle class status (Luffman \& Sussman, 2007; Wotherspoon, 2011). Among Indigenous people who achieved post-secondary education, 3 out of 5 education found jobs in education, recreation, counselling, social sciences, commerce, management, and administration (Wotherspoon, 2011).

Occupation reflects educational credentials and prestige, and in turn class status is affected by the occupational distribution. Knowledge sectors that require university degrees are more likely to lead to employment in occupations that correspond to middle- and upper class status. In our modelling, we expect that once we adjust for occupation gaps in the likelihood of being in the middle- to upper income group should shrink between non-Indigenous and Indigenous populations.

\section{Urbanization}

More Indigenous people are moving into cities, which generally afford greater opportunity for education and employment that contributes to upward income mobility (Ponting, 2005). The number of Indigenous people residing in a Census Metropolitan Area increased by 59.7\% from 2006 to 2016 (Statistics Canada, 2017b). Census results show that there are approximately 92,810 Indigenous people in Winnipeg, 76,205 in Edmonton, 61,46 in Vancouver, and 46,315 in Toronto (Statistics Canada, $2017 \mathrm{~b}$ ). Métis people were more likely to reside in metropolitan areas compared to other Indigenous groups: $62.6 \%$ of Métis were living in metropolitan areas of 30,000 people or more in 2016 (Statistics Canada, 2017b). Winnipeg has the largest Métis population, which was 52,130 in 2016 (Statistics Canada, 2017b). Thus, the larger proportion of Métis living in urbanized areas may explain some of their relative advantages compared to other Indigenous identity groups.

Geographical remoteness is one factor that may contribute to disparities between and among Indigenous Peoples and non-Indigenous peoples. Additionally, people who reside in rural and smaller populations may be paid less on average than people who live in large urban areas due to fewer high paying occupations being available (Beckstead \& Brown, 2005). Also, higher productivity levels in large population centres enable a larger proportion of employers to pay higher wages to workers (Beckstead \& Brown, 2005). Thus, social mobility may be more accessible to those who live in larger centres with a greater number of opportunities and resources, compared to those who remain in smaller or more isolated communities, reinforcing a link between urbanization and social position. 


\section{Methods}

\section{Research Questions}

The following research questions will be answered by the analyses in order to determine the predictors of income class among Indigenous identity groups:

a. How is Indigenous identity group linked to income?

b. Does this relationship differ by Indigenous identity?

c. To what extent does higher education link to middle- and upper income status among Indigenous groups?

d. How do these trends differ by occupation?

e. To what extent does income different between urban and rural areas?

\section{Data}

Our study relies on the 2016 Census, which provides data about demographics, employment, educational background, income, and family structure of the population in Canada. The 2016 Census includes data on both non-Indigenous and Indigenous people in Canada, which allows the analysis to compare socioeconomic outcomes for both populations. The target population are persons living in private dwellings across the nation. The overall response rate was $98.4 \%$. There were 14 reserves that were incompletely enumerated either because community leaders did not consent to participate, or the enumeration was disrupted. These communities were not included in the analyses. The wide range of social, economic, and demographic information as well as the high response rate makes the 2016 Census the most appropriate data for the analysis.

\section{Analytical Sample}

We include non-Indigenous people for comparison and specify four Indigenous identity groups based on respondents' self-identification as Status First Nation, non-Status First Nation, Métis, or Inuit. We exclude other Indigenous identities, such as multiple or other Indigenous identities due to small sample sizes. We restrict the sample to people who are between 25 and 64 years old, as is commonly done to ensure that we focus on the working age population. Since the analysis examines groupings based on income, the analysis excludes individuals whose total Census family income was zero or less. The final analytical sample contains $4,677,880$ respondents.

\section{Variables}

\section{Outcome Variable}

Our focal outcome of interest is a categorical variable that captures lower, middle-, or upper income group membership. We have chosen a quantitative definition of the middle-income group based on the total income of all persons in a Census family. Following Parriag and Chaulk (2013), we define the 
middle-income group as having a total income that falls between $75 \%$ and $150 \%$ of median total income of CAD $\$ 25,500$. Families with an adjusted income below this $75 \%$ threshold are categorized as being in the lower income group, and people who are above the $150 \%$ median threshold are considered part of the upper income group. Outliers displaying extremely high or low levels of income (+/- 3 standard deviations from the mean of the $z$-score) have been removed to avoid undue influence on our regression coefficients.

\section{Predictor Variables}

We are primarily interested in revealing the factors that predict income group membership across Indigenous identity group and in trying to reduce the unexplained differences between these groups. As a result, the analysis focuses primarily on the statistical significance of the Indigenous identityvariable. Non-Indigenous people are the reference group in all analyses with dummy variables for Status First Nations, non-Status First Nations, Métis, and Inuit. Another focal predictor variable is level of education. We divide education into six categories: no diploma, high school diploma, registered apprenticeship or trades certificate, college diploma, university certificate below a bachelor's degree, and university degree at the bachelor's level or higher. Those with a high school diploma are the reference group for the education variable.

Dummy variables for each occupational sector are also included. To determine the occupational sectors, we use the 2011 National Occupational Classification (NOC), which defines the following areas of occupation: (a) management; (b) business, finance, and administration; (c) natural and applied sciences; (d) health occupations; (e) education, law, social, community, and government services; (f) art, culture, recreation, and sport; (g) did not work; (h) trades, transport, and equipment operators;

(i) natural resources, agriculture, and related production occupations; and ( $\mathrm{j}$ ) manufacturing and utilities. The reference group for the occupation variable is sales and services sector.

We use another set of variables for urbanization in the analysis, which is measured by the size of the population centre. Areas with populations of 100,000 people or more are large population centres, areas with populations of 30,000 to 99,999 people are medium population centres, and areas with populations of 1,000 to 29,000 people are small population centres. Rural areas are places with a population of 1,000 or fewer people. Dummy variables for each population centre size are used and rural area is the reference.

\section{Control Variables}

Control variables were used to avoid biased results. To account for gender differences, we employ a binary dummy variable. In addition, we include age as well as age-squared as continuous variables. We control for marital status using dummy variables for single, married, common-law, separated, divorced, and widowed. Single people are the reference group. Labour force status was coded as a dummy variable for full-time employment, part-time employment, and no paid employment. No paid employment is the reference group. We include variables for self-employment and retirement using dummy variables where 1 is yes and 0 is no. Total income includes government transfers (employment insurance, social assistance, etc.); therefore, we also control for this source of income using a dummy value equal to 1 if the transfers received by the household are higher than the median income level of $\$ 25,500$. We also apply a control for the number of people in each household, the number of wage earners, and the 
number of children aged 18 or younger. These variables are continuous. Finally, we control for the province of residence in order to take into account biases related to structural factors such as employment opportunities, natural resource availability, cost of living, and governance transfer adequacy across provinces. Dummy variables are employed for each province namely Ontario, Quebec, Newfoundland and Labrador, Prince Edward Island, Nova Scotia, New Brunswick, Manitoba, Alberta, Saskatchewan, British Columbia, Nunavut, Northwest Territories, and the Yukon Territory. Ontario serves as the reference for this variable.

\section{Statistical Model}

The nature of the outcome variable, an ordinal variable with three categories, generally calls for an ordered logit model, which is designed to model ordinal outcomes with more than two response categories (here we have three). Instead, we use multinomial logit regression models to test the likelihood of being in lower, middle-, or upper income categories. As with binomial logit models, a vector of coefficients is fit to maximize the likelihood of ordered logit models, produce one set of regression coefficients, and handle the ordinal nature of the dependent variable by moving the "cut points" of an unobserved latent variable. Although multinomial logit is less efficient than ordered logit models, we chose to use it because we wanted to present the differences in coefficients of being in the middle-income versus lower income and the upper income versus the lower income group. With only one set of coefficients, this would not have been possible with an ordered logit model.

This article seeks to identify which variables are associated with the attainment of a middle- to upper income status and, to facilitate this, the marginal effects of each main predictor variable are produced. In doing so, we are able to measure the likelihood of falling in each income category per unit change of each predictor variable.

The following model is estimated:

$$
\begin{aligned}
& \eta_{\mathrm{i}}=\alpha+\beta_{1} \text { identity }_{\mathrm{i}}+\beta_{2} \text { education }_{\mathrm{i}}+\beta_{3} \text { occupation }_{\mathrm{i}}+\beta_{4} \text { population centre }_{\mathrm{i}}+\mathrm{e}_{\mathrm{i}} \\
& \eta_{\mathrm{i}}=\alpha+\beta_{1} \text { identity }_{\mathrm{i}}+\beta_{2} \text { education }_{\mathrm{i}}+\beta_{3} \text { occupation }_{\mathrm{i}}+\beta_{4} \text { population centre }_{\mathrm{i}}+\beta_{5} \text { identity education }_{\mathrm{i}}+\mathrm{e}_{\mathrm{i}}
\end{aligned}
$$

Where $\eta_{\mathrm{i}}$ is the class affiliation of every respondent (lower, middle-, and upper income group), $\alpha$ is the intercept and $\beta_{j}$ represents the coefficients of the main predictors for each individual $i$, and $e_{j}$ represents an individual-specific error term. The coefficients are estimated relative to the reference category, which is the lower income group. The second equation shows the added interaction terms where $\beta_{5}$ represents the coefficients of the interacting effects of identity and education.

\section{Results}

\section{Sample Distribution}

Table 1 shows the sample distribution of the outcome variable as well as the independent variables of the analytical sample. 
Table 1. Sample Distribution Across Variables

\begin{tabular}{lc}
\hline \multicolumn{1}{c}{ Variable } & $\%$ \\
\hline Income Group & \\
Lower & $36.0 \%$ \\
Middle & $36.6 \%$ \\
Upper & $27.4 \%$ \\
Identity Group & \\
Non-Indigenous & $95.8 \%$ \\
Status First Nations & $1.9 \%$ \\
Non-Status First Nations & $0.6 \%$ \\
Métis & $1.7 \%$ \\
Inuit & $0.2 \%$
\end{tabular}

\section{Education}

No high school diploma $\quad 11.5 \%$

High school diploma $\quad 23.8 \%$

Apprenticeship or trades $\quad 10.8 \%$

College diploma $\quad 22.5 \%$

Below bachelor's degree $\quad 3.1 \%$

Bachelor's degree or higher $\quad 28.3 \%$

\section{Occupation}

Sales and service $\quad 16.1 \%$

Management $\quad 10.0 \%$

Business, finance, and administrative $\quad 14.0 \%$

Natural and applied sciences $\quad 6.3 \%$

Health services $\quad 6.2 \%$

$\begin{array}{ll}\text { Education } & 10.6 \%\end{array}$

Art, culture, and recreation $\quad 2.4 \%$

No paid work $\quad 16.3 \%$

Trades, transport, and equipment $\quad 12.6 \%$

Natural resources, agriculture, and production $\quad 1.7 \%$

Manufacturing and utilities $\quad 3.9 \%$ 
Table 1. Sample Distribution Across Variables (continued)

\begin{tabular}{|c|c|}
\hline Variable & $\%$ \\
\hline \multicolumn{2}{|l|}{ Population size } \\
\hline Rural & $18.3 \%$ \\
\hline Small urban & $12.1 \%$ \\
\hline Medium urban & $8.8 \%$ \\
\hline Large urban & $60.8 \%$ \\
\hline \multicolumn{2}{|l|}{ Gender } \\
\hline Male & $48.9 \%$ \\
\hline Female & $51.1 \%$ \\
\hline \multicolumn{2}{|l|}{ Retired } \\
\hline No & $95.8 \%$ \\
\hline Yes & $4.2 \%$ \\
\hline \multicolumn{2}{|l|}{ Self-employed } \\
\hline No & $89.7 \%$ \\
\hline Yes & $10.3 \%$ \\
\hline
\end{tabular}

Labour status

No paid work $\quad 18.1 \%$

Full-time work $\quad 69.2 \%$

$\begin{array}{ll}\text { Part-time work } & 12.7 \%\end{array}$

Marital status

Single $\quad 20.8 \%$

Married $\quad 52.3 \%$

Common-law $\quad 15.8 \%$

Separated $3.1 \%$

Divorced $6.6 \%$

Widowed $\quad 1.4 \%$ 
Table 1. Sample Distribution Across Variables (continued)

\begin{tabular}{|c|c|}
\hline Variable & $\%$ \\
\hline \multicolumn{2}{|l|}{ Province } \\
\hline Newfoundland and Labrador & $1.5 \%$ \\
\hline Prince Edward Island & $0.4 \%$ \\
\hline Nova Scotia & $2.6 \%$ \\
\hline New Brunswick & $2.1 \%$ \\
\hline Quebec & $23.2 \%$ \\
\hline Ontario & $38.2 \%$ \\
\hline Manitoba & $3.5 \%$ \\
\hline Saskatchewan & $3.0 \%$ \\
\hline Alberta & $11.8 \%$ \\
\hline British Columbia & $13.4 \%$ \\
\hline Yukon & $0.1 \%$ \\
\hline Northwest Territories & $0.1 \%$ \\
\hline Nunavut & $0.1 \%$ \\
\hline \multicolumn{2}{|l|}{ Received government transfers } \\
\hline No & $50.0 \%$ \\
\hline Yes & $50.0 \%$ \\
\hline \multicolumn{2}{|l|}{ Mean } \\
\hline Number of wage earners & 1.86 \\
\hline Number of people in the household & 3.057 \\
\hline Number of children & 1.672 \\
\hline Age & 45 \\
\hline Age-squared & 2,139 \\
\hline
\end{tabular}

Note. $N=4,677,880$. Source: 2016 Census of Canada. 


\section{Sample Distribution Across Classes}

The distribution across the main predictors for the sample is displayed in Figures 1 to 4. Figure 1 presents the proportion of people in lower, middle-, and upper income groups among non-Indigenous people and Indigenous Peoples.

\section{Figure 1. Distribution of Income Group by Identity}

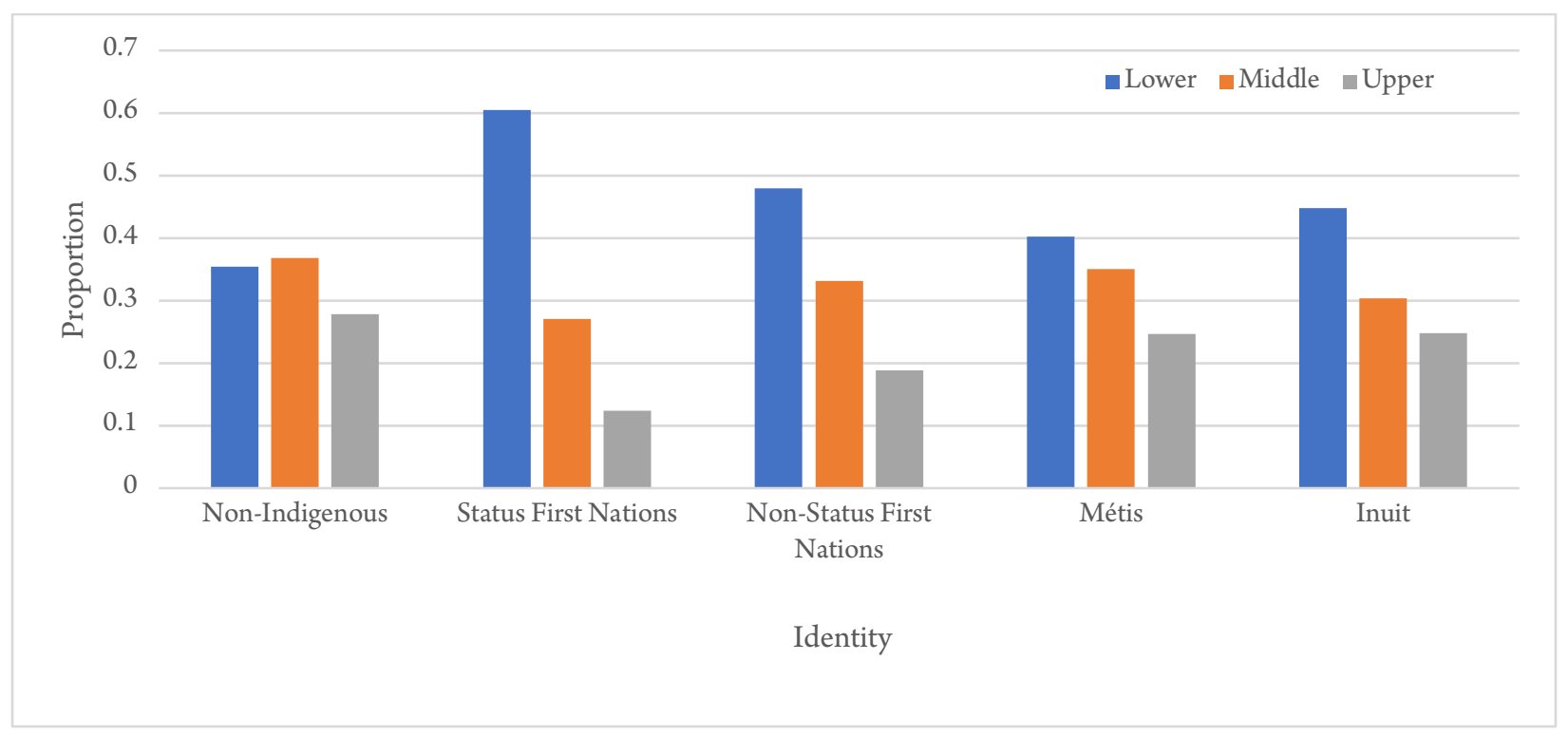

Note. Source: 2016 Census of Canada

Among non-Indigenous people, there appears to be an almost even distribution across income groups: There is a slightly higher proportion of individuals in the middle-income group (36.8\%), followed by $35.4 \%$ in the lower income category, and $27.8 \%$ in the upper income group. However, a disproportionate number of Indigenous people fall into lower income groups, especially among Status First Nations. The majority of Status First Nation people (60.5\%) are in the lower income category, while $27.1 \%$ are in the middle-income and $12.4 \%$ are in the upper income group. Among non-Status First Nation people, $47.9 \%$ are in the lower, $33.2 \%$ are in the middle-, and $18.9 \%$ are in the upper income category, respectively. The income distribution among Métis people more closely resembles that of nonIndigenous people. Among Métis people, $35.1 \%$ are in the middle-income category, while $40.2 \%$ are in the lower income group and $24.7 \%$ are in the upper income group. Approximately $44.8 \%$ of the Inuit group fall within the lower, $30.4 \%$ are in the middle-, and $24.8 \%$ are in the upper income groups.

Figure 2 shows the proportion of people in the lower, middle-, and upper income groups across each level of education. 
Figure 2. Distribution of Class by Education

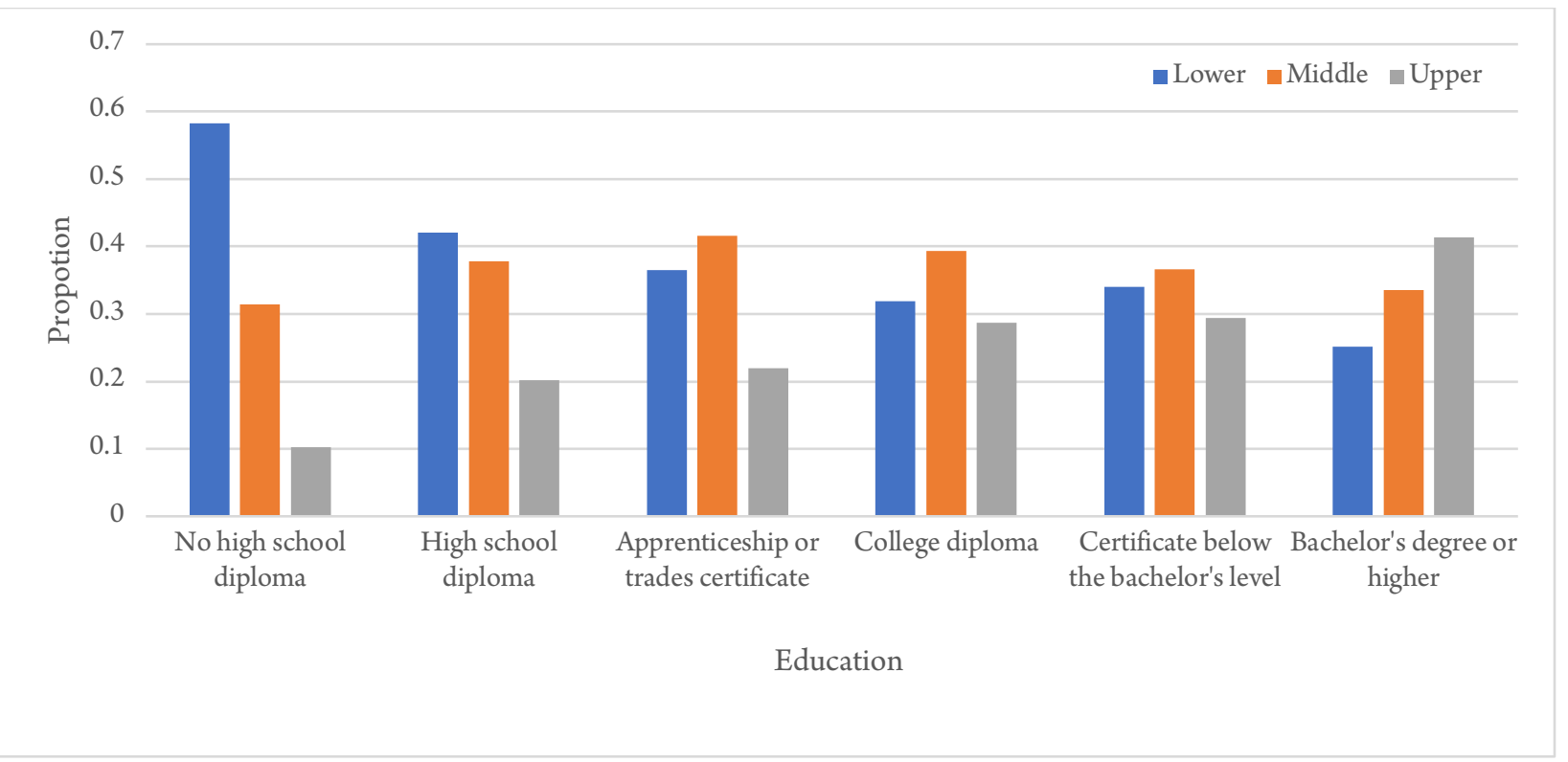

Note. Source: 2016 Census of Canada

The majority of people without a high school diploma fall in the lower income group at $58.3 \%$, while $31.4 \%$ are in the middle-income group, and only $10.3 \%$ fall in the upper income category. Most people who have a high school diploma are also in the lower income category, 38.8\% are in the middle- and $20.2 \%$ are in the upper income categories. Among those who possess a trades or apprenticeship certificate, a high proportion of individuals fall in the middle-income group at $41.6 \%$, while $36.5 \%$ fall in the lower income group and $21.9 \%$ are in the upper income category. Among people with a college degree, $31.9 \%$ are in the lower, $39.4 \%$ are in the middle-, and $28.7 \%$ are in the upper income group, respectively. Further, there is a rise in upper income group membership among those who have a degree below a bachelor's level at $29.4 \%$, while $34 \%$ belong in the lower income group and $36.6 \%$ are in the middle-income group. Lastly, among those with a university degree at the bachelor's level or higher, there are more people who belong in the upper income group: $41.3 \%$ are in the upper income group, $33.6 \%$ are in the middle-income group, and only $25.1 \%$ are in the lower income group. Indeed, larger proportions of people with higher levels of education are found in middle- and upper income levels. 


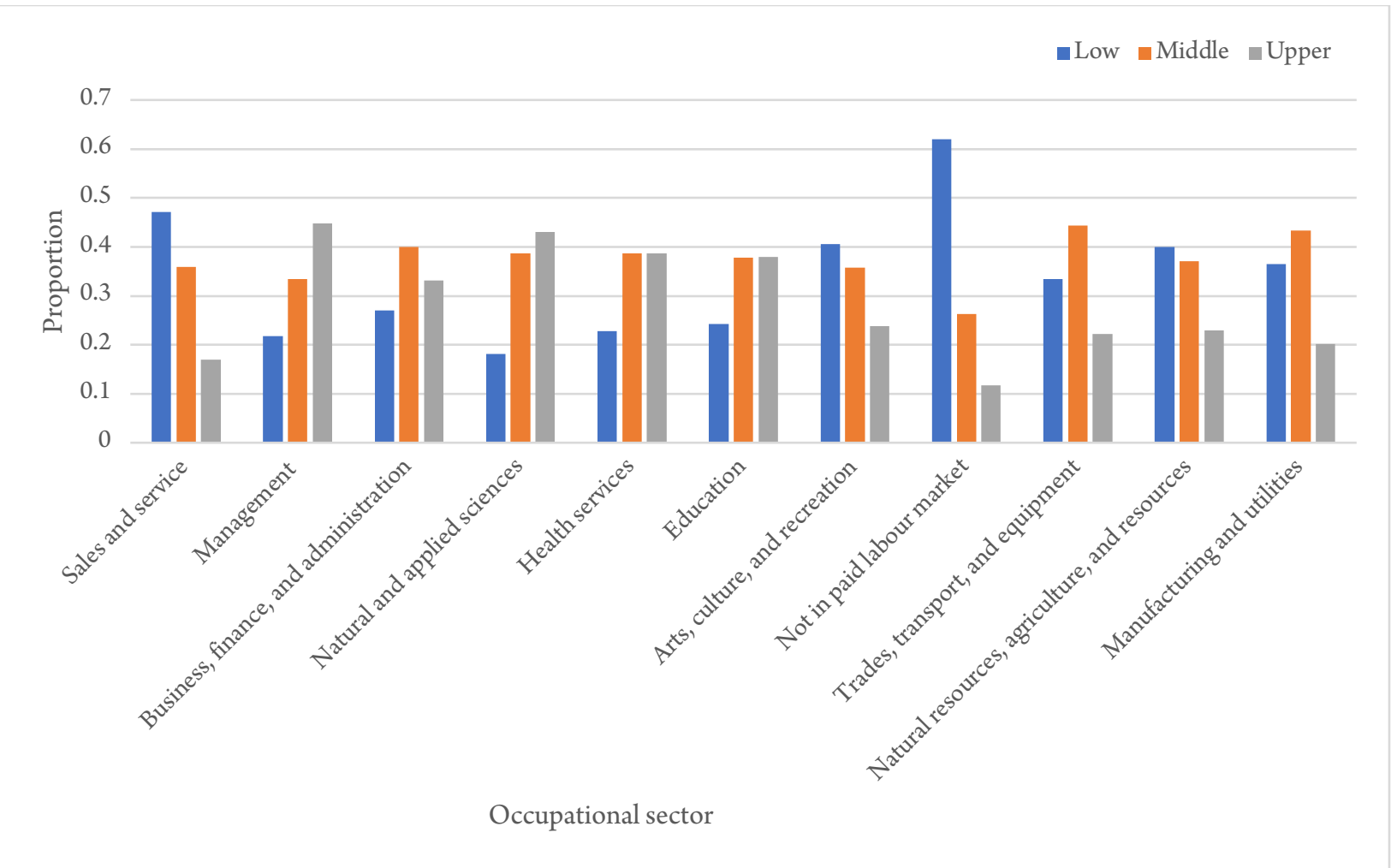

Note. Source: 2016 Census of Canada

People working in the sales and services sector are generally in the lower or middle-income groups, $47.1 \%$ and $35.9 \%$, respectively. Most people in art, culture, and recreation are also found to have lower incomes $(40.5 \%)$, while $35.7 \%$ are in the middle-income group, and $23.8 \%$ are in the upper income group. Among those in manufacturing and utilities, $36.5 \%$ are in the lower, $43.3 \%$ are in the middle-, and $20.2 \%$ are in the upper income group. A higher proportion of people in the sample who work in natural resources fall in the lower income group at $40 \%, 37.1 \%$ are in the middle-income group, and $22.9 \%$ are in the upper income group. As expected, the majority of people who are not in the paid workforce are overrepresented in the lower income group (62\%), and only $26.3 \%$ are in the middle-income group and $11.7 \%$ are in the upper income group.

Further, larger proportions of people are found in the middle- and upper income groups in some occupational fields. For instance, $33.4 \%$ of those in management are in the middle-income group and $44.8 \%$ are in the upper income group. About $40 \%$ of those in business, finance, and administration are in the middle group and $33.1 \%$ are in the upper. Among those in natural and applied sciences, $38.7 \%$ are in the middle-, $43.1 \%$ are in the upper, and only $18.1 \%$ are in the lower income group, respectively. About $38 \%$ are in the middle- and in the upper income groups among those in health services. As well, about $37 \%$ of those in education, law, and social, community and government services are in each of the middle- and upper income groups. A high proportion of middle-income individuals (44.4\%) work in 
trades, transport, and as equipment operators, while $33.4 \%$ are in the lower income group, and only $22.9 \%$ are in the upper income group.

Lastly, the class distribution of population centre size is displayed in Figure 4.

Figure 4. Distribution of Class by Population Centre Size

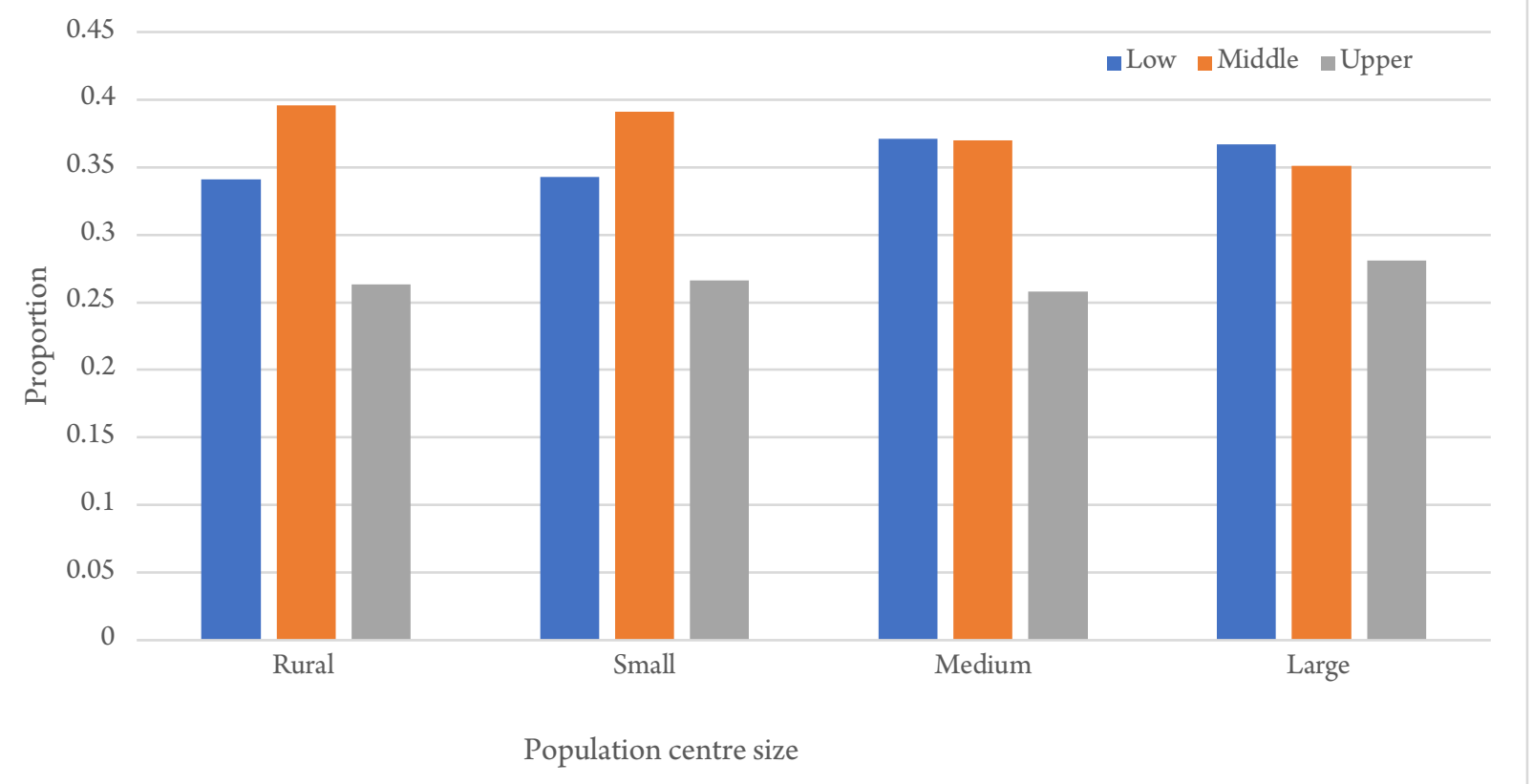

Note. Source: 2016 Census of Canada

Among those living in rural areas, 34.2\% have a lower income level, 39.6\% are in the middle, and 26.3\% are in the upper group. There is a similar income distribution among those living in small population centres where about $34.3 \%, 39.1 \%$, and $26.6 \%$ are in the lower, middle-, and upper income groups, respectively. Among those who live in medium-sized population centres, about $37 \%$ fall in the lower and middle-income groups, and $25.8 \%$ are in the upper group. Lastly, among those living in large population centres, $36.7 \%$ fall in the lower income group, $35.1 \%$ are in the middle-income group, and $28.1 \%$ are in the upper income group.

\section{Multinomial Logistic Regression Results}

The likelihood of belonging in the upper and middle-income groups is determined by running multinomial logistic regression models and producing the relative risk ratios of falling in the upper and middle groups compared to the lower income group (Table 2). The first model tests the effects of identity, education, occupation, and population centre size. The second model includes interaction effects between identity and education (Table 3). In doing so, we can see which factors facilitate higher class status attainment and whether education has varying effects for each identity group. Further, a least likelihood ratio test was employed to test the goodness of fit of both models. We compared the likelihood ratio test results, as well as the Akaike's information criterion and the Bayesian information criterion, and the models presented were a much better fit in every instance. 
Table 2. Multinomial Logit Regression Predicting Income Group

\begin{tabular}{|c|c|c|c|c|c|c|}
\hline \multirow{2}{*}{$\begin{array}{ll} & \text { Model } 1 \\
\text { Predictors } & \end{array}$} & \multicolumn{3}{|c|}{ Middle-income group } & \multicolumn{3}{|c|}{ Upper income group } \\
\hline & rrr & $p$-level & SE & rrr & p-level & SE \\
\hline \multicolumn{7}{|l|}{ Identity } \\
\hline \multicolumn{7}{|l|}{ Non-Indigenous (Ref.) } \\
\hline Status First Nations & 0.52 & $* * *$ & 0.01 & 0.37 & $* * *$ & 0.01 \\
\hline Non-Status First Nations & 0.88 & $* * *$ & 0.01 & 0.84 & $* * *$ & 0.02 \\
\hline Métis & 1.00 & & 0.01 & 1.13 & $* * *$ & 0.01 \\
\hline Inuit & 0.68 & $* * *$ & 0.03 & 0.60 & $* * *$ & 0.03 \\
\hline \multicolumn{7}{|l|}{ Education } \\
\hline No high school diploma & 0.69 & $* * *$ & 0.00 & 0.43 & *** & 0.00 \\
\hline \multicolumn{7}{|l|}{ High school diploma (Ref.) } \\
\hline Apprenticeship or trades certificate & 1.14 & $* * *$ & 0.01 & 1.31 & *** & 0.01 \\
\hline College diploma & 1.22 & $* * *$ & 0.00 & 1.64 & $* * *$ & 0.01 \\
\hline Below bachelor's degree & 1.09 & $* * *$ & 0.01 & 1.60 & *** & 0.01 \\
\hline Bachelor's degree or higher & 1.37 & *** & 0.01 & 3.19 & *** & 0.01 \\
\hline \multicolumn{7}{|l|}{ Occupation } \\
\hline \multicolumn{7}{|l|}{ Sales and services (Ref.) } \\
\hline Management & 1.81 & *** & 0.01 & 4.49 & *** & 0.03 \\
\hline Business, finance, and administration & 1.73 & $* * *$ & 0.01 & 2.83 & *** & 0.01 \\
\hline Natural and applied sciences & 2.48 & *** & 0.02 & 4.74 & *** & 0.04 \\
\hline Health services & 2.21 & *** & 0.01 & 4.37 & *** & 0.03 \\
\hline Education & 1.93 & *** & 0.01 & 3.42 & *** & 0.02 \\
\hline Art, culture, and recreation & 1.54 & *** & 0.01 & 2.19 & *** & 0.02 \\
\hline No work & 1.79 & *** & 0.02 & 3.44 & *** & 0.05 \\
\hline Trades, transport, and equipment & 1.71 & *** & 0.01 & 2.00 & *** & 0.01 \\
\hline $\begin{array}{l}\text { Natural resources, agriculture, and } \\
\text { production }\end{array}$ & 1.39 & *** & 0.01 & 2.20 & *** & 0.03 \\
\hline Manufacturing and utilities & 1.30 & $* * *$ & 0.01 & 1.28 & $* * *$ & 0.01 \\
\hline \multicolumn{7}{|l|}{ Population size } \\
\hline \multicolumn{7}{|l|}{ Rural (Ref.) } \\
\hline Small urban & 1.05 & $* * *$ & 0.01 & 1.06 & *** & 0.01 \\
\hline Medium urban & 0.95 & *** & 0.01 & 0.96 & *** & 0.01 \\
\hline Large urban & 0.80 & $* * *$ & 0.00 & 0.78 & $* * *$ & 0.00 \\
\hline
\end{tabular}

Note. Source: 2016 Census. Reference is lower income group. Control variables are included. rrr $=$ relative risk ratio. $\mathrm{SE}=$ standard error.

${ }^{*} p<.05,{ }^{* *} p<.01,{ }^{* * *} p<.001$ 
Table 3. Multinomial Logit Regression Predicting Income Group Using Interaction Terms

\begin{tabular}{|c|c|c|c|c|c|c|}
\hline \multirow{2}{*}{$\begin{array}{ll} & \text { Model } 2 \\
\text { Predictors } & \end{array}$} & \multicolumn{3}{|c|}{ Middle-income group } & \multicolumn{3}{|c|}{ Upper income group } \\
\hline & rrr & p-level & SE & rrr & $p$-level & SE \\
\hline \multicolumn{7}{|l|}{ Identity } \\
\hline \multicolumn{7}{|l|}{ Non-Indigenous } \\
\hline Status First Nations & 0.52 & *** & 0.01 & 0.40 & $* * *$ & 0.01 \\
\hline Non-Status First Nations & 0.86 & *** & 0.03 & 0.83 & $* * *$ & 0.04 \\
\hline Métis & 0.97 & & 0.02 & 1.16 & $* * *$ & 0.03 \\
\hline Inuit & 0.78 & ** & 0.06 & 0.86 & & 0.08 \\
\hline \multicolumn{7}{|l|}{ Education } \\
\hline No high school diploma & 0.69 & *** & 0.00 & 0.43 & $* * *$ & 0.00 \\
\hline \multicolumn{7}{|l|}{ High school diploma } \\
\hline Apprenticeship or trades certificate & 1.14 & *** & 0.01 & 1.31 & *** & 0.01 \\
\hline College diploma & 1.23 & *** & 0.00 & 1.65 & $* * *$ & 0.01 \\
\hline Below bachelor's degree & 1.09 & *** & 0.01 & 1.60 & *** & 0.01 \\
\hline Bachelor's degree or higher & 1.36 & *** & 0.01 & 3.18 & *** & 0.01 \\
\hline \multicolumn{7}{|l|}{ Occupation } \\
\hline \multicolumn{7}{|l|}{ Sales and services } \\
\hline Management & 1.81 & *** & 0.01 & 4.48 & $* * *$ & 0.03 \\
\hline Business, finance, and administration & 1.73 & *** & 0.01 & 2.83 & *** & 0.02 \\
\hline Natural and applied sciences & 2.48 & *** & 0.02 & 4.74 & $* * *$ & 0.04 \\
\hline Health services & 2.21 & *** & 0.01 & 4.37 & *** & 0.03 \\
\hline Education & 1.93 & $* * *$ & 0.01 & 3.42 & $* * *$ & 0.02 \\
\hline Art, culture, and recreation & 1.54 & *** & 0.01 & 2.19 & *** & 0.02 \\
\hline No work & 1.79 & *** & 0.02 & 3.43 & $* * *$ & 0.05 \\
\hline Trades, transport, and equipment & 1.71 & *** & 0.01 & 2.00 & *** & 0.01 \\
\hline $\begin{array}{l}\text { Natural resources, agriculture, and } \\
\text { production }\end{array}$ & 1.39 & *** & 0.01 & 2.20 & $* * *$ & 0.03 \\
\hline Manufacturing and utilities & 1.30 & *** & 0.01 & 1.28 & *** & 0.01 \\
\hline \multicolumn{7}{|l|}{ Population size } \\
\hline \multicolumn{7}{|l|}{ Rural } \\
\hline Small urban & 1.05 & *** & 0.01 & 1.06 & *** & 0.01 \\
\hline Medium urban & 0.94 & *** & 0.01 & 0.96 & $* * *$ & 0.01 \\
\hline Large urban & 0.80 & *** & 0.00 & 0.78 & *** & 0.00 \\
\hline
\end{tabular}


Table 3. Multinomial Logit Regression Predicting Income Group Using Interaction Terms (continued)

\begin{tabular}{|c|c|c|c|c|c|c|}
\hline Model 2 & \multicolumn{3}{|c|}{ Middle-income group } & \multicolumn{3}{|c|}{ Upper income group } \\
\hline Predictors & rrr & $\begin{array}{c}p- \\
\text { level }\end{array}$ & SE & rrr & $\begin{array}{c}p- \\
\text { level }\end{array}$ & SE \\
\hline \multicolumn{7}{|l|}{ Identity ${ }^{*}$ Education } \\
\hline Status First Nations ${ }^{*}$ No high school diploma & 0.94 & * & 0.02 & 1.01 & & 0.04 \\
\hline Status First Nations * Apprenticeship or trades certificate & 0.92 & ** & 0.03 & 0.93 & & 0.04 \\
\hline Status First Nations ${ }^{*}$ College diploma & 0.93 & ** & 0.03 & 0.78 & *** & 0.03 \\
\hline Status First Nations * Below bachelor's degree & 1.05 & & 0.06 & 0.78 & ** & 0.06 \\
\hline Status First Nations* bachelor's degree or higher & 1.57 & *** & 0.06 & 1.29 & *** & 0.06 \\
\hline Non-Status First Nations ${ }^{*}$ No high school diploma & 1.06 & & 0.05 & 1.23 & ** & 0.09 \\
\hline $\begin{array}{l}\text { Non-Status First Nations *Apprenticeship or trades } \\
\text { certificate }\end{array}$ & 0.95 & & 0.05 & 0.92 & & 0.07 \\
\hline Non-status First Nations ${ }^{*}$ College diploma & 0.91 & * & 0.04 & 0.85 & ** & 0.05 \\
\hline Non-status First Nations * Below bachelor's degree & 1.38 & ** & 0.16 & 1.50 & ** & 0.21 \\
\hline Non-status First Nations * Bachelor's degree or higher & 1.35 & *** & 0.08 & 1.31 & *** & 0.09 \\
\hline Métis ${ }^{*}$ No high school diploma & 1.06 & & 0.03 & 1.25 & *** & 0.05 \\
\hline Métis * Apprenticeship or trades certificate & 1.07 & * & 0.03 & 1.04 & & 0.04 \\
\hline Métis ${ }^{*}$ College diploma & 0.91 & ** & 0.02 & 0.80 & *** & 0.03 \\
\hline Métis * Below bachelor’s degree & 1.14 & * & 0.07 & 1.07 & & 0.08 \\
\hline Métis * Bachelor’s degree or higher & 1.31 & *** & 0.05 & 1.13 & ** & 0.05 \\
\hline Inuit * No high school diploma & 0.78 & ** & 0.07 & 0.62 & *** & 0.07 \\
\hline Inuit * Apprenticeship or trades certificate & 0.75 & * & 0.09 & 0.52 & *** & 0.07 \\
\hline Inuit ${ }^{*}$ College diploma & 0.81 & & 0.09 & 0.56 & $* * *$ & 0.07 \\
\hline Inuit * Below bachelor's degree & 1.91 & * & 0.63 & 1.64 & & 0.56 \\
\hline Inuit * Bachelor's degree or higher & 1.65 & ** & 0.31 & 1.43 & & 0.28 \\
\hline
\end{tabular}

Note. Source: 2016 Census. Reference is lower income group. Control variables are included. rrr $=$ relative risk ratio. $\mathrm{SE}=$ standard error.

${ }^{*} p<.05,{ }^{* *} p<.01,{ }^{* * *} p<.001$ 
The marginal effects at the means show the probability to fall in each income category while holding all variables at their mean. The marginal effects of the main predictor variables, identity, education, occupation, and population centre size are produced in order to present a clear interpretation of how these factors affect the likelihood of falling in lower, middle-, and upper income categories. Table 4 shows the chances of being in each income group by identity.

The results in Table 4 show that Status First Nations have a higher likelihood of falling in the lower income group (49\%), followed by Inuit at $41 \%$. Non-Status First Nation people are $34 \%$ more likely to be in the lower income group. Métis and non-Indigenous people have similar likelihoods of being in the lower income group at $30 \%$ and $31 \%$, respectively.

Additionally, non-Indigenous, Métis and non-Status First Nation people have similar chances of belonging in the middle-income category (48\%, $46 \%$, and $46 \%$, respectively). Inuit are $43 \%$ and Status First Nations are $39 \%$ more likely to be in the middle-income group.

In terms of the likelihood of being in the upper income category, Métis are 24\% more likely, followed by non-Indigenous people at $21 \%$. Non-Status First Nations are 20\%, while Inuit are $17 \%$ more likely to be part of the upper income group, respectively. Finally, Status First Nations appear to be the most disadvantaged - with a lower likelihood of being in the upper income group at $12 \%$. Thus, to answer our first and second research questions, we see that there are disparities between the non-Indigenous and Indigenous identity groups, with Status First Nation people being more likely to be lower income. The results also show that Métis people have a similar likelihood of being in the middle- and upper income groups as non-Indigenous people.

Education is critical to middle- and upper income attainment, addressing our third research question. Having no high school diploma increases the likelihood of occupying a lower economic position by $47 \%$, almost 40 percentage points higher than the likelihood of being in the upper income group. At the other end of the spectrum, the likelihood of being a member of the upper income group is $23 \%$ for those with at least a bachelor's degree, and this probability increases by 10 points with a degree above a bachelor's level. Although education appears to be a strong factor for distributing individuals between lower and upper income groups, it has little effect for middle-income category membership, which was similar across education levels. These findings warrant further investigation in future research. 
Table 4. The Marginal Effects of the Main Predictors of Income Category

\begin{tabular}{|c|c|c|c|c|c|c|c|c|c|}
\hline \multirow[b]{2}{*}{ Predictors } & \multicolumn{3}{|c|}{ Lower income } & \multicolumn{3}{|c|}{ Middle income } & \multicolumn{3}{|c|}{ Upper income } \\
\hline & $\mathrm{dy} / \mathrm{dx} \mathrm{x}^{\mathrm{a}}$ & $p$-level & SE & $\mathrm{dy} / \mathrm{dx}$ & $p$-level & SE & $\mathrm{dy} / \mathrm{dx}$ & $p$-level & SE \\
\hline \multicolumn{10}{|l|}{ Identity } \\
\hline Non-Indigenous & 0.31 & $* * *$ & 0.00 & 0.48 & $* * *$ & 0.00 & 0.21 & $* * *$ & 0.00 \\
\hline Status First Nations & 0.49 & *** & 0.00 & 0.39 & $* * *$ & 0.00 & 0.12 & *** & 0.00 \\
\hline Non-Status First Nations & 0.34 & $* * *$ & 0.00 & 0.46 & $* * *$ & 0.00 & 0.20 & $* * *$ & 0.00 \\
\hline Métis & 0.30 & $* * *$ & 0.00 & 0.46 & *** & 0.00 & 0.24 & *** & 0.00 \\
\hline Inuit & 0.41 & $* * *$ & 0.01 & 0.43 & $* * *$ & 0.01 & 0.17 & $* * *$ & 0.01 \\
\hline \multicolumn{10}{|l|}{ Education } \\
\hline No high school diploma & 0.47 & *** & 0.00 & 0.44 & *** & 0.00 & 0.09 & $* * *$ & 0.00 \\
\hline High school diploma & 0.36 & $* * *$ & 0.00 & 0.48 & $* * *$ & 0.00 & 0.16 & $* * *$ & 0.00 \\
\hline $\begin{array}{l}\text { Apprenticeship or trades } \\
\text { certificate }\end{array}$ & 0.32 & *** & 0.00 & 0.49 & *** & 0.00 & 0.19 & $* * *$ & 0.00 \\
\hline College diploma & 0.29 & *** & 0.00 & 0.49 & $* * *$ & 0.00 & 0.22 & *** & 0.00 \\
\hline Below bachelor's degree & 0.31 & $* * *$ & 0.00 & 0.46 & $* * *$ & 0.00 & 0.23 & $* * *$ & 0.00 \\
\hline $\begin{array}{l}\text { Bachelor's degree or } \\
\text { higher }\end{array}$ & 0.23 & $* * *$ & 0.00 & 0.43 & $* * *$ & 0.00 & 0.34 & $* * *$ & 0.00 \\
\hline \multicolumn{10}{|l|}{ Occupation } \\
\hline Sales and service & 0.46 & $* * *$ & 0.00 & 0.42 & $* * *$ & 0.00 & 0.12 & $* * *$ & 0.00 \\
\hline Management & 0.26 & $* * *$ & 0.00 & 0.43 & $* * *$ & 0.00 & 0.31 & $* * *$ & 0.00 \\
\hline $\begin{array}{l}\text { Business, finance, and } \\
\text { administrative }\end{array}$ & 0.30 & $* * *$ & 0.00 & 0.48 & $* * *$ & 0.00 & 0.22 & $* * *$ & 0.00 \\
\hline $\begin{array}{l}\text { Natural and applied } \\
\text { sciences }\end{array}$ & 0.22 & $* * *$ & 0.00 & 0.50 & $* * *$ & 0.00 & 0.28 & $* * *$ & 0.00 \\
\hline Health services & 0.24 & $* * *$ & 0.00 & 0.49 & $* * *$ & 0.00 & 0.27 & $* * *$ & 0.00 \\
\hline Education & 0.27 & $* * *$ & 0.00 & 0.48 & $* * *$ & 0.00 & 0.24 & $* * *$ & 0.00 \\
\hline $\begin{array}{l}\text { Art, culture, and } \\
\text { recreation }\end{array}$ & 0.34 & $* * *$ & 0.00 & 0.47 & $* * *$ & 0.00 & 0.19 & $* * *$ & 0.00 \\
\hline No work & 0.28 & $* * *$ & 0.00 & 0.46 & $* * *$ & 0.00 & 0.25 & $* * *$ & 0.00 \\
\hline $\begin{array}{l}\text { Trades, transport, and } \\
\text { equipment }\end{array}$ & 0.32 & $* * *$ & 0.00 & 0.51 & $* * *$ & 0.00 & 0.17 & $* * *$ & 0.00 \\
\hline $\begin{array}{l}\text { Natural resources, } \\
\text { agriculture, and } \\
\text { production }\end{array}$ & 0.35 & $* * *$ & 0.00 & 0.45 & $* * *$ & 0.00 & 0.20 & $* * *$ & 0.00 \\
\hline $\begin{array}{l}\text { Manufacturing and } \\
\text { utilities }\end{array}$ & 0.40 & $* * *$ & 0.00 & 0.47 & $* * *$ & 0.00 & 0.13 & $* * *$ & 0.00 \\
\hline
\end{tabular}


Table 4. The Marginal Effects of the Main Predictors of Income Category (continued)

\begin{tabular}{|c|c|c|c|c|c|c|c|c|c|}
\hline \multirow[b]{2}{*}{ Predictors } & \multicolumn{3}{|c|}{ Lower income } & \multicolumn{3}{|c|}{ Middle income } & \multicolumn{3}{|c|}{ Upper income } \\
\hline & $\mathrm{dy} / \mathrm{dx^{2 }}$ & $p$-level & SE & $\mathrm{dy} / \mathrm{dx}$ & $p$-level & SE & $\mathrm{dy} / \mathrm{dx}$ & $p$-level & SE \\
\hline \multicolumn{10}{|l|}{ Population centre size } \\
\hline Rural & 0.29 & *** & 0.00 & 0.49 & $* * *$ & 0.00 & 0.22 & *** & 0.00 \\
\hline Small urban & 0.28 & *** & 0.00 & 0.50 & $* * *$ & 0.00 & 0.23 & $* * *$ & 0.00 \\
\hline Medium urban & 0.30 & *** & 0.00 & 0.48 & *** & 0.00 & 0.22 & *** & 0.00 \\
\hline Large urban & 0.33 & *** & 0.00 & 0.46 & *** & 0.00 & 0.20 & *** & 0.00 \\
\hline
\end{tabular}

Note. Source: 2016 Census. Marginal effects give the probability of being in each income group, while holding other variables at their mean. Control variables are included.

${ }^{a} \mathrm{dy} / \mathrm{dx}$ indicates the rate of change of $\mathrm{y}$, the outcome, with respect to $\mathrm{x}$, the predictor.

${ }^{*} p<.05,{ }^{* *} p<.01,{ }^{* * *} p<.001$

In terms of occupation, we can see in Table 4 that some occupational sectors are linked to lower economic standing, while others are linked to higher income status. People working in the sales and service sector are at the greatest risk of having a lower income ( $46 \%$ likelihood). Other occupations such as arts, entertainment, and accommodation, as well as trades, natural resources, and manufacturing, carry a 30\% likelihood of being in the lower income group. Next, across all occupation sectors people have a similar likelihood of being in the middle-income group. Most notably, jobs in the natural sciences, health services, education services, and trades have about a 50\% likelihood of placing people at the middle-income level. Lastly, people who work in management, natural sciences, health services, and education services have a higher chance of being in the upper income group, at almost a $30 \%$ likelihood. Occupational sectors thus have an impact on class affiliation, wherein working in the sales and service sector carries a higher risk of lower income status, while those working in knowledge and high-skill occupational sectors such as management, sciences, health, and education are more likely to be found to be in a higher income position, answering our fourth research question.

Regarding the marginal effects of population centre size on class belonging in Table 4 (Research Question 5), we find that those who reside in large urban areas have a lower likelihood of being in the middle- and upper income groups. Those who are either living in rural areas or medium-sized population centres are more likely to have lower economic status (by about 29\%). Moreover, those who reside in large population centres are at higher risk of being in the lower income category (33.4\% more likely). Additionally, the chances of being in the middle-income group is quite similar across the population centres sizes. Finally, the likelihood of belonging in the upper income group is $23 \%$ for those living in small population centres, $22 \%$ for those in rural areas and medium population centres, and $20 \%$ for those living in large population centres. There are no stark differences in the marginal effects across the different population centre sizes. However, those in medium and large urban areas are found to be slightly more likely to be in the lower income group.

\section{The Centrality of Education for Exiting Lower Income Status}

The results above demonstrate the importance of several factors for exiting lower income status, but none looks at Indigenous populations explicitly. In this section, we turn to this issue more directly, 
focusing explicitly on how educational attainment shapes income distribution among Indigenous identity groups relative to the non-Indigenous population. We do this by interacting educational attainment with each of our Indigenous and non-Indigenous populations. The second multinomial logistic regression (not shown) includes interaction terms between identity and education and finds that some groups indeed benefit more from higher education than others. The marginal effects of the interaction terms in the second model shows the predicted probability of each group to fall in either lower, middle-, or upper income groups at each level of education.

Figure 5 presents the marginal effects of education on the likelihood to belong in the lower, middle, and upper class for non-Indigenous people while holding other variables at their means.

\section{Figure 5. Marginal Effects of Non-Indigenous Identity and Education on Income Category}

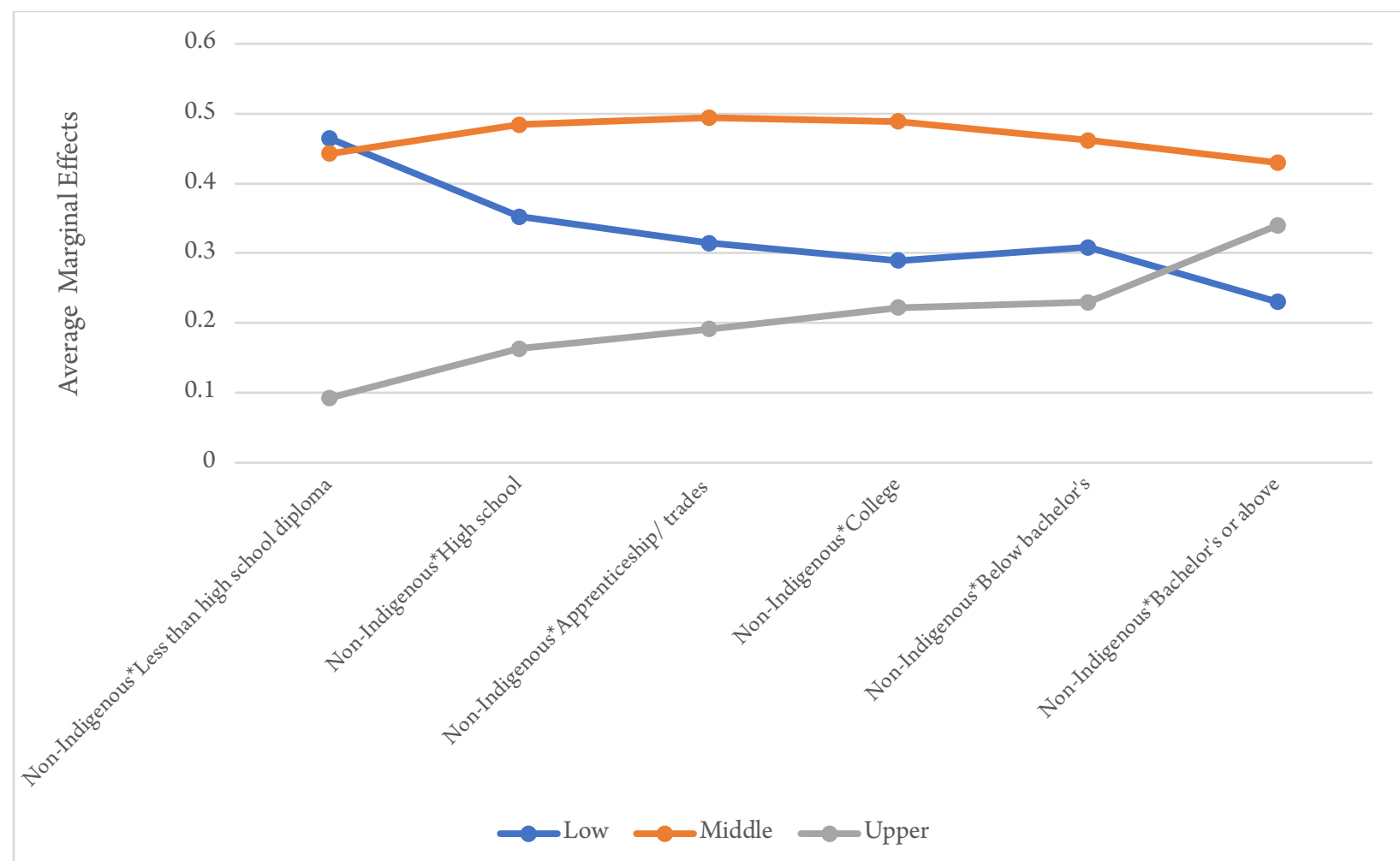

Note. Source: 2016 Census of Canada. The marginal effects at the means are significant at $p<.001$. The marginal effects give the probability to fall in each income group while holding other variables at their mean.

Having less than a high school diploma increases the likelihood that non-Indigenous people will be in the lower income category by $46 \%$. The chances of them falling in the lower income group decreases the higher their level of education: Those who have at least a bachelor's degree have a $23 \%$ likelihood of being in the lower income group. Non-Indigenous people are likely to fall in the middle-income group by almost 50\% whether they have a high school diploma, apprenticeship or trades certificate, college diploma, or a university certificate below the bachelor-level. They have a slightly lower likelihood, about $43 \%$, of being middle in the middle-income group if they have at least a bachelor's degree. Non- 
Indigenous people with a college or university certificate below the bachelor's level have a $22 \%$ likelihood of being in the income group. Lastly, non-Indigenous people who have at least a bachelor's degree are almost $40 \%$ more likely to have the highest income level.

Among Indigenous identity groups, Status First Nation people have a relatively high probability of lower income status despite post-secondary education. Figure 6 shows the marginal effects of the interaction term between Status First Nations identity and education while other variables are at their means.

Figure 6. Marginal Effects of Status First Nations Identity and Education on Income Category

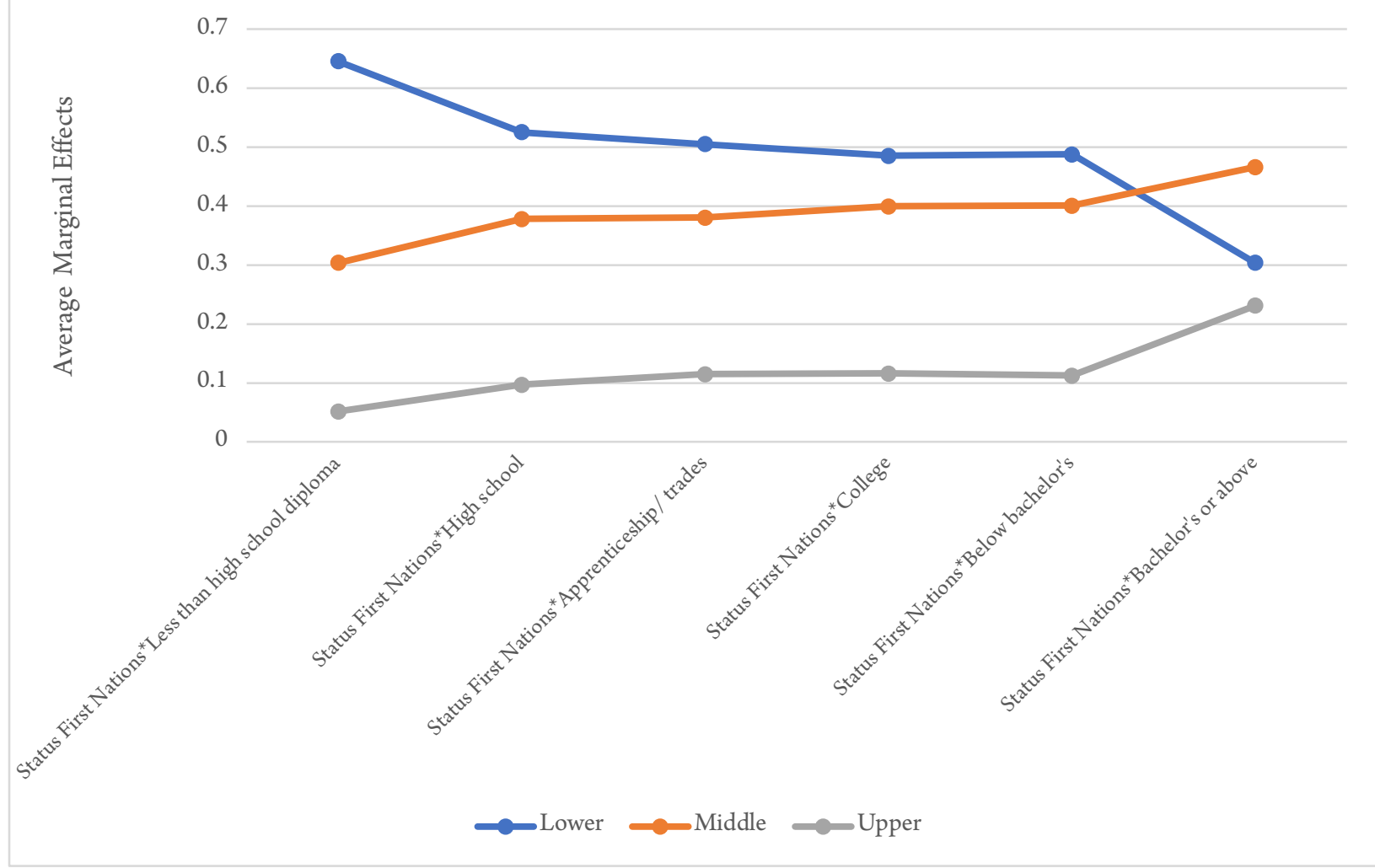

Note. Source: 2016 Census of Canada. The marginal effects at the means are significant at $p<.001$. The marginal effects give the probability of being in each income group while holding other variables at their mean.

Status First Nation people without a high school diploma are $65 \%$ more likely to be in the lower income group. The likelihood of being in the lower income group decreases with higher education but even with an apprenticeship or trades certificate, a college diploma, or a university degree below the bachelor's level, Status First Nation people are almost 50\% more likely to be in the lower economic status group. Additionally, those who have at least a bachelor's degree are still about $30 \%$ more likely to fall in the lower income group. Further, the likelihood of falling in the middle-income group is lower among Status First Nations. Those with a high school, apprenticeship or trades certificate, college diploma, or university degree below a bachelor's level have an approximately $40 \%$ chance of having an income at the middle level. Status First Nation people's chances of being in the middle-income group increases only slightly with at least a bachelor's degree. Status First Nation people are found to have lower chances of 
being in the upper income group across education levels compared to non-Indigenous people. Status First Nations people who have an apprenticeship or trades certificate, college diploma, or university degree below a bachelor's level have an $11 \%$ probability of being in the upper income group. Those who have a bachelor's degree or higher have only a $23 \%$ chance of having an income at the upper level.

Among non-Status First Nations, post-secondary education decreases their likelihood of being in the lower income group, which is shown in Figure 7.

\section{Figure 7. The Marginal Effects of Non-Status First Nations Identity and Education on Income}

\section{Category}

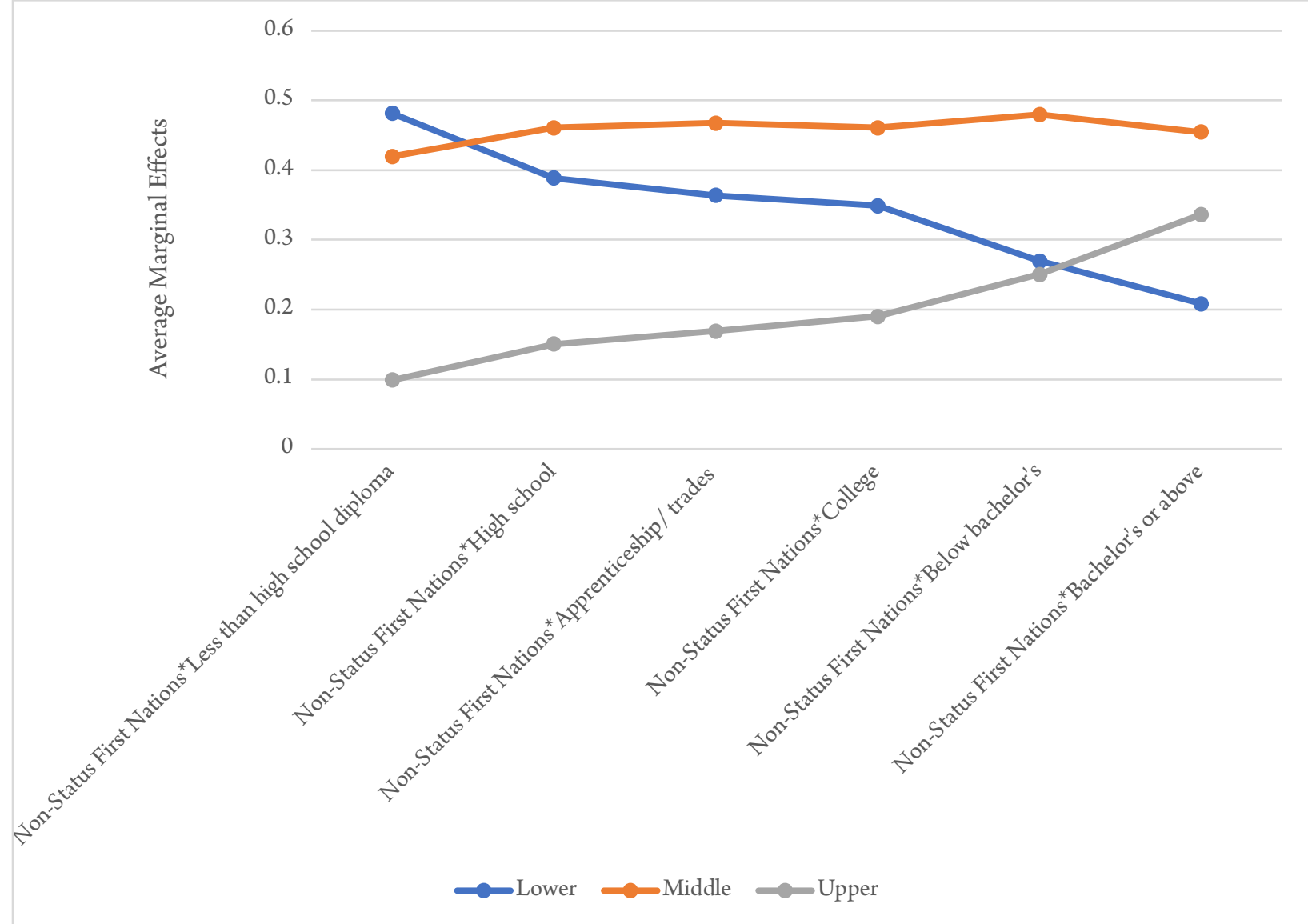

Note. Source: 2016 Census of Canada. The marginal effects at the means are significant at $p<.001$. The marginal effects give the probability of falling in each income group while holding other variables at their mean.

Non-Status First Nation people with a high school diploma have a 39\% chance of being in the lower income group, while those who have an apprenticeship or trades certificate have a $36 \%$ and those who have a college degree have a $35 \%$ likelihood. A university education decreases the chances of falling in the lower income group: The likelihood of being in the lower income group among individuals with a university degree below the bachelor's level is only $27 \%$ and with at least a bachelor's degree is $21 \%$. Like 
non-Indigenous people, non-Status First Nation people have an almost 50\% chance of being in the middle-income group with a high school diploma, apprenticeship or trades certificate, college diploma, or below bachelor's-level university education. Those who possess a bachelor's degree or higher have a $45 \%$ chance of being in the middle-income group. Lastly, non-Status First Nation people appear to have a better chance of reaching a higher income standing with higher education - those who have at least a bachelor's degree have a 33\% likelihood of being in the upper income group.

With higher education, Métis people have slightly better odds of being in the middle- or upper income classes compared to First Nations. Figure 8 shows the marginal effects of the interaction terms for Métis identity and education.

Figure 8. The Marginal Effects of Métis Identity and Education on Income Category

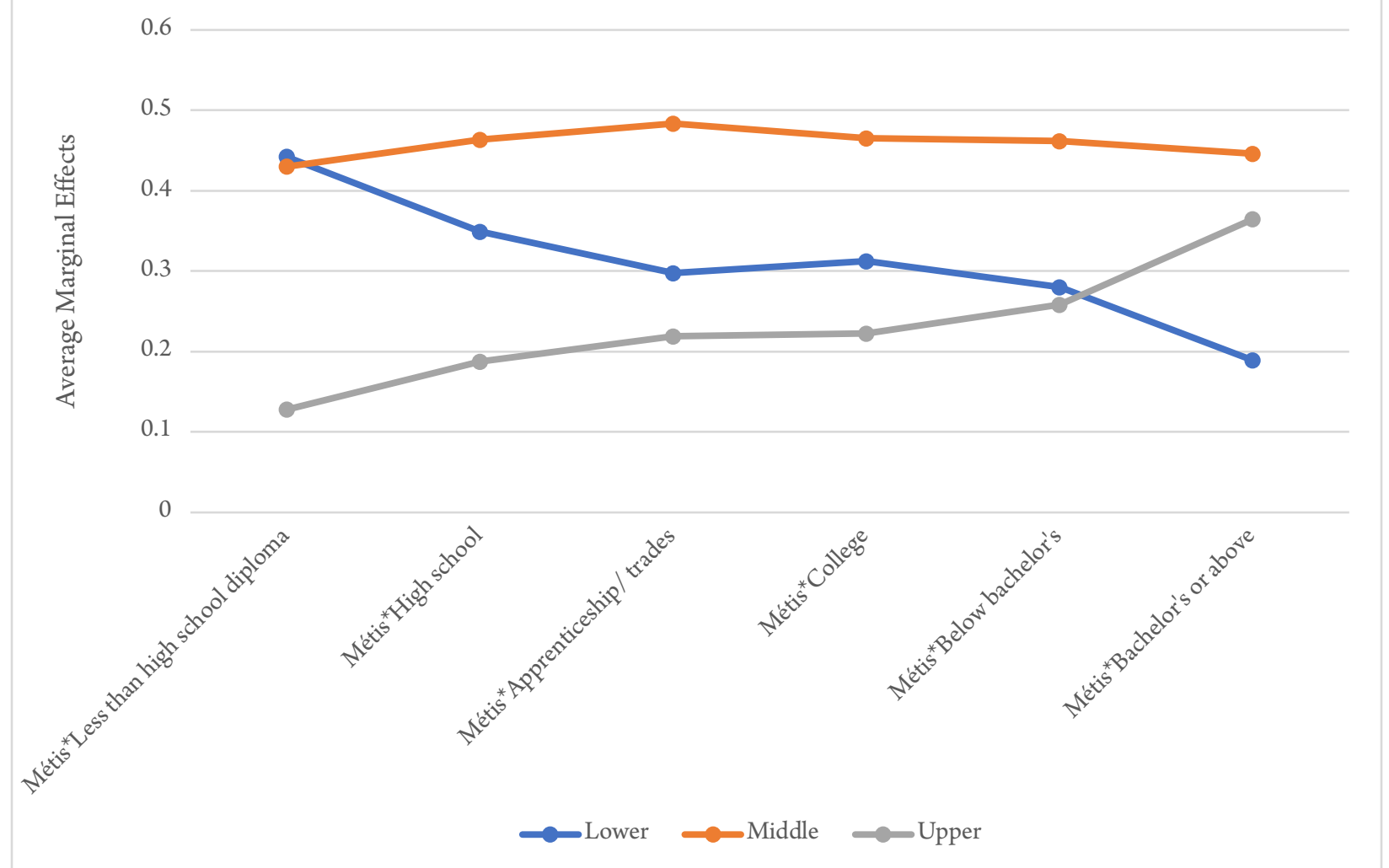

Note. Source: 2016 Census of Canada. The marginal effects at the means are significant at $p<.001$. The marginal effects give the probability of falling in each income group while holding other variables at their mean.

Métis people with at least a bachelor's degree have a 19\% chance of being in the lower income group. Métis people also follow a similar trend as non-Indigenous people and non-Status First Nation people, wherein those who have at least a high school diploma have an almost 50\% chance of reaching the middle-income level. Métis people also see an improved income status with higher education. With at least a bachelor's degree, they have a $36 \%$ chance of being upper class, which is slightly higher than nonIndigenous people. 
Finally, Figure 9 shows the marginal effects of the interaction term between Inuit identity and education while other variables are at their mean. Among Inuit, having education attainment below the university degree level is associated with a higher likelihood of falling in the lower income group. However, having at least a bachelor's degree is associated with a lower chance of being in the lower income group. Inuit who have a high school diploma, apprenticeship or trades certificate, or college diploma have a greater than $40 \%$ likelihood of being in the middle-income group. Moreover, those who have a university certificate below the bachelor's level have a 52\% chance of being in the middle-income group, while those who possess a bachelor's degree or higher have a $46 \%$ likelihood. Finally, Inuit also have a higher likelihood to reach the upper income level with higher education, particularly college or university education.

Figure 9. The Marginal Effects of Inuit Identity and Education on Income Category

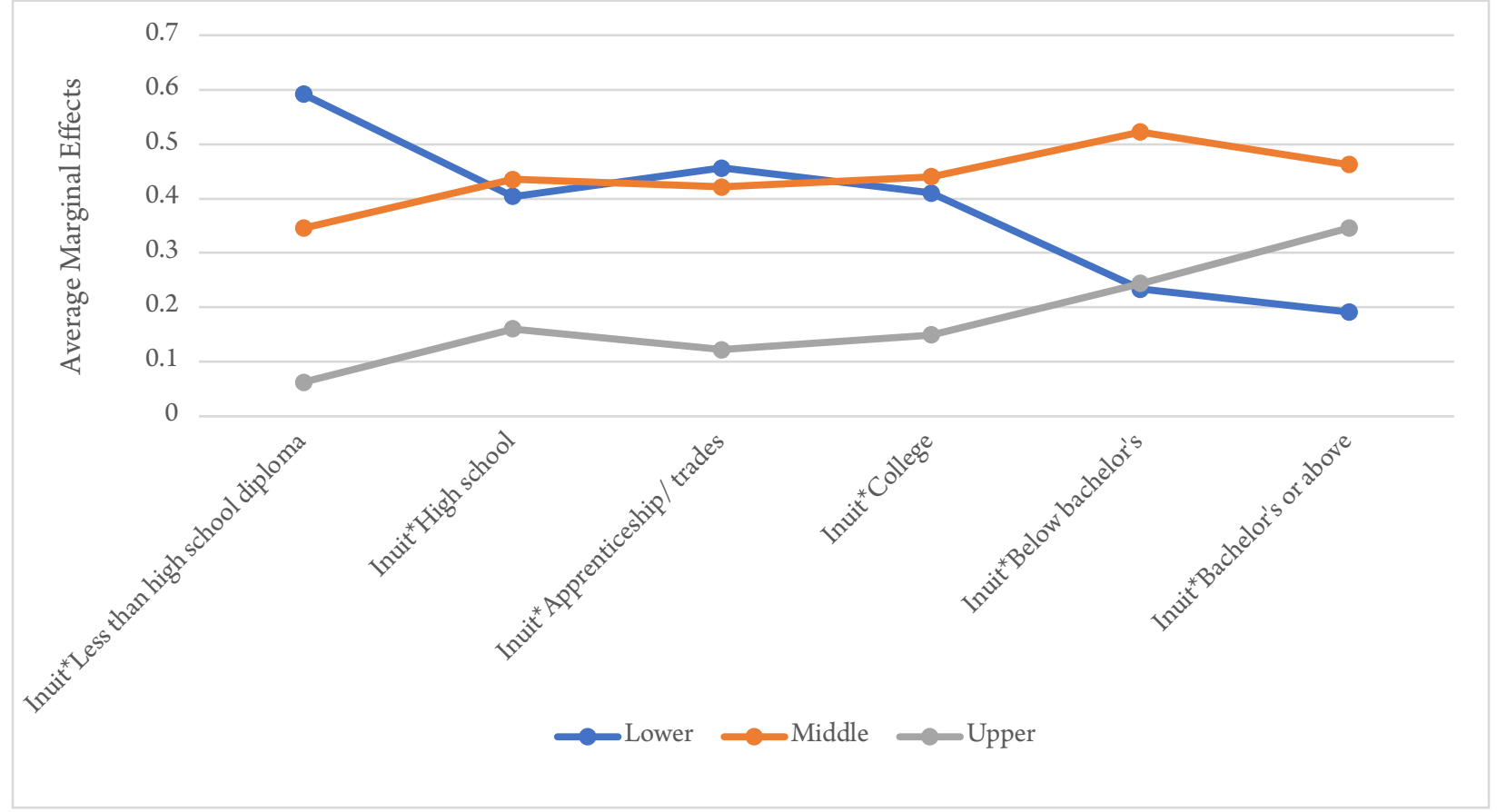

Note. Source: 2016 Census of Canada. The marginal effects at the means are significant at $p<.001$. The marginal effects give the probability to fall in each income group while holding other variables at their mean.

\section{Discussion}

The class distribution in Canada shows that inequalities persist between non-Indigenous people and Indigenous people, as well as between Indigenous identity groups. Characteristics examined in this study, such as identity, occupation, and population centre size, uncover where these inequalities lie, and which factors help drive income-based class membership. The results show that Indigenous people have lower chances of having a middle-level income than non-Indigenous people, all else being equal.

Additionally, First Nations and Inuit have a lower likelihood of being at the upper income level. Status First Nation people had the greatest disadvantage, while Métis people were comparatively advantaged. 
Thus, income disparities persist not only between non-Indigenous and Indigenous people, but also between Indigenous identity groups. These inequalities suggest factors that are specific to or more prevalent among Indigenous identity groups, which influence income attainment. For instance, the relative economic disadvantage among Status First Nations warrants attention to systematic barriers. Henceforth, the larger social context, including the history of colonization and State control, must be considered in relation to the socioeconomic position of Indigenous Peoples.

Some other factors such as occupation and population centre size are also found be linked to income. Compared to the sales and service sector, all other job sectors increased the likelihood of being in the middle- and upper income groups. In particular, knowledge sectors, such as the natural and applied sciences, health services, and management, seem to facilitate higher income standing. Finally, those who reside in small population centres are better able to reach the middle- to upper income levels, whereas living in a medium to large population centre lowers the chances. Although larger urban areas may provide more opportunities, there are also higher rates of poverty and homelessness among Indigenous people (Belanger et al., 2012). Thus, there are economic disparities that persist within the structures of people's geographic residence.

For all groups, nothing matters more for class mobility than education, particularly for exiting lower socioeconomic status and joining the upper class ${ }^{1}$; for most groups, middle-income attainment is largely independent of education. However, educational benefits are not uniformly distributed across identity groups. A curious result is that Status First Nation people with a college diploma or a university degree below the bachelor's level have a higher likelihood of being economically disadvantaged. However, having at least a bachelor's degree increases their likelihood of being in the higher income group. Although having at least a bachelor's degree is an advantage to all groups, some benefit more than others. Most notably, a bachelor's degree or higher makes membership in the middle- or upper income groups more likely among Status First Nations. However, non-Indigenous and Métis people appear to benefit the most from post-secondary education from the apprenticeship level up to at least a bachelor's degree. Among Inuit, having at least a college diploma is an almost a necessary condition for higher income attainment. More research into identity group-specific dynamics and systemic barriers underlying socioeconomic disadvantage is needed, as is targeted investment in education among groups experiencing barriers to education.

\section{Conclusion}

This project investigates the demographic composition of membership in the lower, middle-, and upper income classes by identity group. In terms of policy implications, the findings suggest that, while a sizable proportion of Indigenous people are in the middle- or upper income groups, disparities still exist between Indigenous and non-Indigenous populations, and between Indigenous identity groups. The income segmentations that exist among Indigenous people are rooted in Canada's history of paternalistic policy and legislation, which set legal, social, and economic lines that systematically marginalized Indigenous Peoples. Moving forward, policy development must pay more attention to education as it is a critical part of Indigenous people's upward mobility. The basic human capital model,

\footnotetext{
${ }^{1}$ To support this claim, we ran a series of stepwise regressions, and for all groups, the largest gains in model fit came from adding education characteristics.
}

Published by Scholarship@Western, 2021 
in which higher education and some occupational sectors place people in better positions in the social hierarchy, is supported by the results. Education is indeed one of several ways that individuals reach and maintain middle- and upper class status (Goux \& Maurin, 2012). For Indigenous Peoples, this statement is especially true, and has even been called "the new buffalo" (Stonechild, 2006). Thus, government policy should support educational attainment among Indigenous people and address barriers to postsecondary education.

The study has some methodological limitations that should be noted. First, as with many studies that look at the impact of education, we have an unknown amount of selectivity across education categories. It is possible that those who attended university, for example, would have done well economically due to pre-existing abilities for which we are incorrectly crediting education for higher standing. Second, those who come from a middle- or upper class family backgrounds may be more likely to pursue higher education, which would overestimate the true effects of education. The analyses aimed to show the link between these factors and income group belonging in order to point to which areas policy may be targeted in order to improve the socioeconomic position of marginalized groups. Third, there are 14 reserves and settlements that were incompletely enumerated and thus not included in the data, so our results may not accurately reflect trends in those locations. Fourth, the dataset is cross-sectional, so we are only able to provide a snapshot of social class at the time of data collection.

Applying the interaction terms of Indigenous identity and education allows us to examine how these variables intersect with respect to income class. Our findings indeed suggest that some Indigenous identity groups are better able to access higher education, which is in turn associated with higher income status. We also show that the returns on education differ by Indigenous identity group, with Status First Nation people experiencing relative disadvantage, while Métis people experience education trends that follow a pattern similar to non-Indigenous people.

\section{References}

Becker, G. (1992). Human capital and the economy. Proceedings of the American Philosophical Society, 136(1), 85-92.

Belanger, Y. D., Gabrielle W., \& Awosoga, O. (2012). Assessing urban Aboriginal housing and homelessness in Canada. National Association of Friendship Centres (NAFC) and the Office of the Federal Interlocutor for Métis and Non-Status Indians (OFI). https://homelesshub.ca/ sites/default/files/Final_Belanger_Housing_and_Homeless - 6 _May 2012.pdf

Bonesteel, S. (2008). Canada's relationship with Inuit: A history of policy and program development. Indian and Northern Affairs Canada. https://www.aadnc-aandc.gc.ca/ DAM/DAM-INTER-HQ/STAGING/texte-text/inuit-book_1100100016901_eng.pdf

Bougie, E., Kelly-Scott, K., \& Arriagada, P. (2013). The education and employment experiences of First Nations Peoples living off-reserve, Inuit, and Métis: Selected findings from the $2012 \mathrm{Aboriginal}$ Peoples survey. Statistics Canada. https://www150.statcan.gc.ca/n1/pub/89-653-x/89-653$\underline{\mathrm{x} 2013001-\mathrm{eng} . \mathrm{htm}}$ 
Beckstead, D., \& Brown, M. (2005). Provincial income disparities through an urban-rural lens. Canadian Economic Observer, 18(8). https://www150.statcan.gc.ca/n1/pub/11-010$\underline{\mathrm{x} / 00805 / 8449 \text {-eng.htm }}$

Coates, K. (1999). Being Aboriginal: The cultural politics of identity, membership and belonging among First Nations in Canada. Canadian Issues, 21, 23-41.

De Graaf, N. (1991). Distinction by consumption in Czechoslovakia, Hungary, and the Netherlands. European Sociological Review, 53, 103-112. https://doi.org/10.1093/ oxfordjournals.esr.a036605

DiMaggio, P., \& Mukhtar, T. (2004). Arts participation as cultural capital in the United States, 19822002: Signs of decline? Poetics, 32(2), 169-194. https://doi.org/10.1016/j.poetic.2004.02.005

Distasio, J., Sylvester, G., \& Mulligan, S. (2005). Home is where the heart is and right now that is nowhere: An examination of hidden homeless among Aboriginal Peoples in Prairie cities. Institute of Urban Studies, University of Winnipeg. https://www.homelesshub.ca/ sites/default/files/attachments/NRP_009_Hidden_Aboriginal_Homelessness.pdf

Fan, L., Brownlee, K., Nazim, H., \& Raymond, N. (2017). Returns to education and occupations for Canadian Aboriginal People. International Journal of Social Economics, 44(12), 2224-2237.

George, P., \& Kuhn, P. (1994). The size and structure of Native-White differentials in Canada. Canadian Journal of Economics, 27(1), 20-42. https://doi.org/10.2307/135800

Gerber, L. M. (2014). Education, employment, and income polarization among Aboriginal men and women in Canada. Canadian Ethnic Studies, 46(1), 121-144. https://doi.org/10.1353/ ces.2014.0015

Gordon, C. E., White, J. P. (2014). Indigenous educational attainment in Canada. The International Indigenous Policy Journal, 5(3). https://doi.org/10.18584/iipj.2014.5.3.6

Goux, D., \& Maurin, É. (2012). Enquête sur les classes moyennes [Survey of the middle classes]. Seuil.

Heisz, A. (2007). Income Inequality and Redistribution in Canada: 1976 to 2004. Ottawa: Statistics Canada. https://www150.statcan.gc.ca/n1/pub/11f0019m/2007298/4143888-eng.htm

Indian Act R.S.C., 1985, c. I-5. https://laws-lois.justice.gc.ca/eng/acts/I-5/page$\underline{1 . h t m l}$ txthl=tract+lands+land\#s-2

Kambourov, G., \& Manovskii, I. (2009). Occupational specificity of human capital. International Economic Review, 5O(1), 63-115. https://doi.org/10.1111/j.1468-2354.2008.00524.x

Katz-Gerro, T. (2002). Highbrow cultural consumption and class distinction in Italy, Israel, West Germany, Sweden, and the United States. Social Forces, 81(1), 207-229. https://doi.org/ $\underline{10.1353 / \text { sof.2002.0050 }}$ 
Kraaykamp, G., \& Nieuwbeerta P. (2000). Parental background and lifestyle differentiation in Eastern Europe: Social, political, and cultural intergenerational transmission in five former socialist countries. Social Science Research, 29(1), 92-122. https://doi.org/10.1006/ssre.1999.0655

Lamb, D. (2013). Earnings inequality among Aboriginal groups in Canada. Journal of Labour Research, 34(2), 224-240. https://doi.org/10.1007/s12122-013-9158-0

Lamb, D., Yap, M., \& Turk, M. (2018). Aboriginal/Non-Aboriginal wage gaps in Canada: Evidence from the 2011 National Household Survey. Industrial Relations, 73(2), 225-251. https://doi.org/10.7202/1048569ar

Lopéz-Sintas, K., \& Katz-Gerro, T. (2005). From exclusive to inclusive elites and further: Twenty years of omnivorousness and cultural diversity in arts participation in the USA. Poetics, 33(5), 299319. https://doi.org/10.1016/i.poetic.2005.10.004

Luffman, J., \& Sussman D. (2007). The Aboriginal labour force in Western Canada. Perspectives on Labour and Income, 19(1), 13-27. https://www150.statcan.gc.ca/n1/en/pub/75-001$\underline{\mathrm{x} / 10107 / 9570 \text {-eng.pdf?st=d8cbGZ8F }}$

McHahon, T. (2014, August 22). Why fixing First Nations education remains so far out of reach: Aboriginal youth face a fate that should horrify Canadians and there's an obvious fix. Maclean's. https://www.macleans.ca/news/canada/why-fixing-first-nations-education-remains-so-far-outof-reach/

Menzies, P. (2006). Intergenerational trauma and homeless Aboriginal men. Canadian Review of Social Policy, 8, 1-24.

Moyser, M. (2017). Aboriginal People living off reserve and the labour market: Estimates from the Labour Force Survey, 2007-2015. Statistics Canada. https://www150.statcan.gc.ca/ $\underline{\mathrm{n} 1 / \mathrm{pub} / 71-588-\mathrm{x} / 71-588-\mathrm{x} 2017001 \text {-eng.htm }}$

Oelke, N., Thurston, W., \& Turner, D. (2016). Aboriginal homelessness: A framework for best practice in the context of structural violence. International Indigenous Policy Journal, 7(2). https://doi.org/10.18584/iipj.2016.7.2.5

Parriag, A., \& Chaulk, P. (2013). The urban Aboriginal middle-income group in Canada: A demographic profile. Aboriginal Policy Studies, 2(2), 34-63. https://doi.org/ $\underline{10.5663 / \text { aps.v2i2.19005 }}$

Patrick, C. (2014). Aboriginal homelessness in Canada: A literature review. Canadian Homelessness Research Network Press.

Pendakur, K., \& Pendakur, R. (2011). Aboriginal income disparity in Canada. Canadian Public Policy, 37(1), 61-83. https://doi.org/10.3138/cpp.37.1.61 
Peterson, R., \& Simkus, A. (1992). How musical tastes mark occupational status groups. In M. Lamont \& M. Fournier (Eds.), Cultivating differences: Symbolic boundaries and the making of inequality (pp. 152-186). University of Chicago Press.

Ponting, R. (2005). The new urban middle class. In H. H. Hiller (Ed.), Urban Canada (pp.138-167). Oxford University Press Canada.

Pruden, J. G., \& Kirkup, K. (2021, May 31). Indigenous leaders say discovery of children's remains at Kamloops residential school is beginning of national reckoning. The Globe and Mail. https://www.theglobeandmail.com/canada/article-indigenous-leaders-call-for-nationalreckoning-after-childrens-remains/

Statistics Canada. (2017a). Aboriginal Peoples and the labour market. https://www150.statcan.gc.ca/n1/daily-quotidien/170316/dq170316d-eng.htm

Statistics Canada. (2017b). Aboriginal Peoples in Canada: Key results from the 2016 census. https://www150.statcan.gc.ca/n1/daily-quotidien/171025/dq171025a-eng.htm

Stonechild, B. (2006). The new buffalo: The struggle for Aboriginal post-secondary education in Canada. University of Manitoba Press.

White, J., \& Peters, J. (2013). Editors' commentary: The challenges in improving Indigenous educational attainment. International Indigenous Policy Journal, 4(4), 3-8. https://doi.org/10.18584/iipj.2013.4.4.6

Wotherspoon, T. (2011). Prospect for a new middle class among urban Aboriginal People. In D. Newhouse \& E. Peters (Eds.), Not strangers in these parts: Urban Aboriginal Peoples (pp. 145165). Policy Research Initiative. http://www.urbancentre.utoronto.ca/pdfs/elibrary/ Canada_Urban-Aboriginal-Peo.pdf

Wotherspoon, T., \& Satzewich, V. (1993). First Nations: Race, class and gender relations. Nelson Canada.

Zangelidis, A. (2008). Occupational and industry specificity of human capital in the British labour market. Scottish Journal of Political Economy, 55(4), 420-443. https://doi.org/10.1111/ j.1467-9485.2008.00460.x 